\title{
Guidelines for Regional Advisers on Consultant Posts in the Psychiatry of Old Age
}

\section{General comments}

The development of an effective psychiatric service for the elderly depends upon allocation of adequate resources. Nationally over $37 \%$ of first psychiatric admissions and $33 \%$ of readmissions are over 65 years of age and where an active psychiatric service for old people develops, this proportion is likely to increase. The additional resources needed for long-term care for severely demented people have to be taken into account. A good candidate, trained in psychiatry of the elderly, is unlikely to consider a post where the provision is inadequate. The sessions allocated to old age psychiatry should be seen in the context of the total number of consultant sessions in psychiatry.

\section{Sources of further advice}

Further advice on the guidelines can be obtained from Regional representatives of the Section for the Psychiatry of Old Age. A list of these representatives can be obtained from the College.

\section{Consultant time}

For every 10,000 old people in an average community there will be demand for around 100 acute psychiatric admissions annually. Because of this high rate of demand and because of the heavy commitment to work in the community, the maximum number of old people for whom one full-time consultant can provide a service will be approximately 22,000. A part-time commitment can be calculated on the basis of a maximum of 2,000 old people per session. The number of sessions should be increased by $50 \%$ in a teaching district. The suggested general allocation of sessions, including non-clinical sessions such as planning, teaching and research liaison and academic and other links (e.g. with social services) should be stated. Membership of committees, planning groups and on call duties should be delineated.

\section{General statement}

A general statement of the post and how it fits into overall plans for local psychiatric services and especially plans for services for old people should be included in particular:

\section{(i) The psychiatric service}

(a) The catchment area (and whether or not coterminous with the old age psychiatry catchment area); (b) number of acute and long-stay beds; (c) number of sessions of consultant time; (d) number of trainees; (e) number of clinical assistant sessions; (f) number of day hospital places and (g) number of community psychiatric nurses.

There should be a clear statement on the local policy of allocation of responsibility for the population aged over 65 .
In particular this should refer to the arrangements and criteria which are to be used for the transfer of patients from the 'general adult' service to the 'old age' service.

\section{(ii) The geriatric service}

(a) The catchment area (and whether or not coterminous with the psychiatric service for the elderly); (b) total number of consultant sessions; (c) consultant sessions available to the psychiatric service for the elderly; (d) total number of geriatric beds; (e) number of geriatric beds on an acute hospital site and (f) number of geriatric day hospital places.

(iii) Social services

(a) The area served (and whether or not coterminous with the health services and the size of the population over 65); (b) number of Part 3 residential places and day centre places; (c) number of EMI home places and EMI day places; (d) whether or not any personnel are available with special expertise relating to the elderly and the proposed social work input into the psychiatric service for the elderly; (e) details of sheltered housing. The psychiatric commitment to social services facilities should be described.

\section{(iv) Planning}

The local arrangements for planning should be described: e.g. whether plannning for old age psychiatry is primarily through the old age planning team or the mental illness planning team, the nature of links between the two and the role of the appointee in this planning process. For administration, details of local management arrangements and, in particular, the nature of links with the geriatric service should be described, as should any special facilities (e.g. orthopaedic geriatric unit) with which there are likely to be special links.

(v) Private and voluntary sector

Some indication of the nature and extent of local private and voluntary sector residential and nursing home facilities for the elderly should be included together with any psychiatric input to these services in terms of clinical time and staff training.

\section{Ont-patientu, office and other faclitidien, ese. teachlng} space, andio vibeal aids etc.

\section{Type of poet}

The type of post, full-time or part-time should be stated, also whether the post is full time in Psychiatry of Old Age or if it is a 'Special responsibility' post, the rescional 
commitment. Because of service pressures 'Special interest' (as opposed to 'Special responsibility') posts are not appropriate in Psychiatry of Old Age.

\section{7a. Facilities}

The population to be served should be clearly defined as: (a) total all ages; (b) number over 65; (c) number over 75.

The population projections over the next 10 years should be included wherever possible. There should be a description of the type of catchment area in terms of geography and social structure and there should be comment on any aspects of the catchment population which will make the service different from average.

There should be a clear understanding of what facilities are to be allocated to the psychiatrist for the elderly for functional illness and dementia services respectively, whether or not these facilities are, in practice, integrated. The acute facilities should be on a District General Hospital site.

1. Functional illness service for the elderly (from within the provision for general psychiatry):

(i) acute assessment beds $0.5 / 1,000$ population;

(ii) long-stay beds $0.17 / 1,000$ population;

(iii) day places $0.65 / 1,000$ population (to be shared by the in-patient group: the above figures are 'pro rata' from DHSS recommendations.)

2. Dementia services for the elderly (additional to the provision for general psychiatry) $12-20$ beds $/ 200,000$ general population. (Recommended by DHSS in HM 72 (71)). This figure is now inadequate because such beds generally have an important treatment and rehabilitation function as well as being used for assessment and because the proportion of very old people in the population has increased since the date of the DHSS recommendation. A reasonable figure for such a unit would be 1 bed $/ 1,000$ population over 65 years.

3. Psychogeriatric long-stay $2.5-3$ beds/1,000 population over 65 years. Simply to state the number of long-stay patients in a mental hospital aged over 65 years does not constitute provision of long stay beds-vacancies may be very slow to come in these beds (occupied chiefly by aged chronic schizophrenics). The bed provision should be generally available for elderly patients with severe dementia. The increasing number of very old people and the increasingly longevity of this sub-group of dementia sufferers means the higher end of this norm will now be needed.

4. Day Hospital places for severely demented old people 2-3/1,000 elderly population.

\section{7b. Other staff}

The following figures apply to an 'average' district (15\% over 65 years). Districts with very high (or low) concentrations of elderly people will have to make appropriate adjustments.

(a) Trainees. The psychiatric service for the elderly must have an adequate provision of junior trainees who should be included in a rotational scheme. Some of these might be GP trainees. This should be related both to the expected work load and training needs.

(b) Senior Registrars. Old Age services should have an appropriate share in Regional Senior Registrar Training arrangements bearing in mind the immediate need to increase the availability of Senior Registrar training in Old Age Psychiatry.

(c) Clinical assistants/Medical assistants. The service should attract a share of clinical assistant/medical assistant sessions which will reflect the availability of these and the way in which they are used within the psychiatric service.

(d) Secretarial. There must be adequate provision: a secretary is a key member of the team. The secretary attached to a consultant psychiatrist for the elderly will have considerable responsibility for management and liaison. If possible she should be employed as a personal secretary with higher clerical grading. 0.5 to 1 full-time secretary is desirable for every 10,000 old people served. A day hospital will need additional receptionist/clerktypist staffing if it is to work effectively.

(e) Community psychiatric nurses. 1 nurse per 5,000 population over the age of 65 .

(f) Other supporting staff. Other appropriate input will be needed from occupational therapy, psychologists, physiotherapists etc. The level of this staffing should be at least of the order of one occupational therapist per 10,000 elderly and one physiotherapist and clinical psychologist per 20,000 elderly. In many districts higher levels of provision in these disciplines will be justified. Access to speech therapy should be available, though a designated number of sessions is usually not necessary.

(g) Special areas. A $50 \%$ increase in consultant time will be needed in a teaching area. More staff are needed if facilities are on several sites (as often is the case).

8. Division of responsibilities between the sharing of facilities with other clinicians including geriatricians and other psychiatrists should be made clear. If an inadequate number of sessions is available to serve the whole of a district's elderly population, inevitably some of the work will remain the responsibility of the general psychiatrists. If this is the case the areas of responsibility should be clearly defined by sectorisation.

\section{Summary}

For a district service with a total population of 200,000 and 30,000 over the age of 65 the following are required:

\section{Functional illness}

(i) 15 acute beds; 
(ii) 5 new long-stay beds;

(iii) 20 day places.

Dementia service

(i) psychogeriatric unit-30 beds;

(ii) long-stay beds- -90 beds;

(iii) day places $-60-90$.

Consultant time

Fifteen sessions. In a teaching area there should be $50 \%$ increase in consultant time.

Non-consultant medical staff

(i) junior trainees: Numbers should be related both to the expected work load and to the training needs.

(ii) senior registrars: wherever possible a psychiatric service should be able to provide training for a Senior Registrar. There is a considerable demand for such training and all senior registrar schemes should include at least one training post in old age psychiatry.

(iii) clinical assistant according to availability and deployment.
Other staff

1.5 to 3 secretaries with additional clerical time for the day hospital. Six community psychiatric nurses, 3 occupational therapists, 1.5 physiotherapists, 1.5 clinical psychologists and other appropriate staff.

The facilities described above are not ideal but are those required to establish a credible psychiatric service for the elderly. Shortage of money at the present time means that promises made in job descriptions are unlikely to be fulfilled in the short term and therefore a post should not be approved unless facilities are actually available or definitely funded. Health authorities would be unlikely to create posts for surgeons without beds and operating facilities. They must be made aware that a psychiatric service likewise cannot operate without a basic provision. Phrases such as "it is hoped to provide" or "are under discussion" when used in regard to key facilities (e.g. beds, day places) are not to be regarded as meeting the need for these essentials.

J. WATTIS

D. NeAL

R. PHILPOT

\section{Notes for the Guidance of Regional Advisers}

\section{Consultant posts for alcohol and drug dependence}

1. The psychiatric services are responsible for a growing number of patients with alcohol or drug problems. Nationally, the facilities for specialised treatment of alcohol or drug misuse are patchy. The defects in the provision of psychiatric services are in process of correction. There is a need for regional or subregional units to act as centres of expertise, to stimulate and guide developing services, to treat and advise individual patients, and to promote research. There is also a requirement for consultant psychiatrists to provide special services at district level for alcohol and drug dependent patients.

2. Regional Advisers are required to obtain advice from the Regional Representative in all specialities that appoint Representatives to regions. Each health region has a Representative for alcohol and drug dependence. Certain regions possess a Speciality Tutor who can be consulted. Further advice can also be obtained from the Chairman of the Substance Misuse Section.

3. The majority of the consultants working in the dependencies will be general consultants with a special responsibility. Training and experience will have been gained in registrar and senior registrar rotations or by secondment of consultants to special units for drug dependence (see point 9 below). The consultant in a health district will usually be expected to provide at least four sessions for the dependencies, and, where special regional units exist, the consultant may spend the whole or the majority of his time in the field.

4. A general description of the post should be offered that will include reference to the overall plans for local psychiatric services.

5. Details should be provided of the population that will be served. A reference may be needed to special situations; for example, inner city problems, geographical difficulties in providing a service, and the existing statutory and voluntary facilities.

6. Type of post:

(a) The description should state whether the post is fulltime or part-time, and whether an option is provided.

(b) There are several kinds of post that are involved. An average district requires four sessions for all types of substance misuse. Largely rural districts may require less sessions, but districts in certain urban conurbations may require more than four sessions, or a full-time post. These district posts should be described as involving 'a responsibility for....' and not 'a special interest in....', since the first phase defines more firmly the subspeciality duties and requires precision regarding the number of relevant sessions.

There is a further distinction between the posts. Some deal only with alcoholic patients, some only with drug dependent patients, while others involve both 